\title{
Presentación / Introduction
}

\author{
Wolfram Nitsch
}

Desde su descubrimiento y conquista en el siglo XVI, el Nuevo Mundo ha sido percibido como un continente de largas distancias y de paisajes intransitables. Por ende, las técnicas y redes de comunicación siempre han desempeñado un papel decisivo en América Latina, en el sentido doble de la palabra «comunicación» destacado por Harold A. Innis (1991), a saber, con respecto tanto a la transmisión de mensajes como al transporte de personas y mercancías. Numerosos observadores atentos han subrayado esta importancia de las comunicaciones espaciales. Ya el Inca Garcilaso de la Vega consideró los caminos, canales y puentes construidos por los Incas con el mismo interés que su sistema de escritura o de correos (Nitsch 2011); y el vanguardista argentino Julio Payró hasta propuso «hacer una historia del arte basada en la evolución de los medios de locomoción» (Payró 2005: 49). Sin embargo, a diferencia de los medios de comunicación en sentido estricto, las técnicas y redes de transporte solo recientemente comienzan a ser tratadas con la atención debida en la historia literaria y cultural de Latinoamérica. Como el recién publicado diccionario de Términos clave para los estudios de movilidad en América Latina (Zunino Singh/ Giucci/Jirón 2018), que sin duda dará lugar a varias investigaciones correspondientes, el presente número monográfico se propone remediar este descuido.

Un trabajo transdisciplinario sobre las culturas latinoamericanas del transporte se puede basar en tres paradigmas de investigación discutidos en estos últimos años. En primer lugar, la filosofía y la antropología de la técnica, tal como se han desarrollado en Francia, ofrecen algunos conceptos aptos para analizar con mayor precisión la dimensión mediológica de los medios de locomoción, ya subrayada por la escuela de Toronto. La mecanología de Jacques Lafitte, elaborada por Gilbert Simondon, permite analizar los medios de transporte como máquinas duales, si no universales: como máquinas activas, dado que transforman la energía que las propulsa en un movimiento por el espacio exterior, y al mismo tiempo máquinas pasivas, ya que constituyen un espacio interior donde asignan un sitio particular al pasajero (Lafitte 1972). La teoría del actor-red, propuesta por Bruno Latour e inspirada por André Leroi-Gourhan, posibilita describir además de manera sutil el complicado proceso de mediación que se arma entre el vehículo con su programa específico, contenido en la técnica material, y el usuario que lo utiliza empleando técnicas corporales (Latour 1999). En segundo lugar, la teoría de la movilidad, esbozada sobre todo en la geografía cultural anglo-americana, presenta reflexiones interesantes sobre la producción social del desplazamiento humano. Así, Tim Cresswell distingue entre el «movimiento» físico abstracto y la «movilidad» concreta, formada por lo que George Revill llama la «cultura del transporte», a saber, el conjunto de prácticas y de representaciones común de un colectivo de pasajeros (Cresswell 2006, Revill/Duvall 2005). En tercer lugar, existen algunos trabajos más o menos recientes que trazan la historia de los transportes en América Latina desde una perspectiva no solo política y económica, sino también social y cultural. Entre ellos, cabe citar ante todo La vida cultural del automóvil y El viaje colectivo de Guillermo Giucci (Giucci 2007, Giucci/Errázuriz 2018), pero también los estudios sobre el automovilismo argentino de Melina Piglia (2014) o bien el libro reciente Un diablo al que le llaman tren del historiador colombiano 
Javier Ortiz Cassiani (2018). En estos trabajos se vislumbra a menudo el papel importante de la literatura y del cine con respecto a las culturas del transporte. Tales representaciones textuales o visuales de los medios de locomoción y de las experiencias que ellos hacen posibles no solo contribuyen a cierta mitología de los vehículos, tal como la esbozó Roland Barthes en un ensayo de semiología cultural (Barthes 1993); además, destacan con frecuencia algunos efectos colaterales de la locomoción vehicular raramente abordados por ingenieros o economistas. De este modo, constituyen un archivo de las sensaciones y de las emociones experimentados por los pasajeros, cuyo estudio promete nuevas luces acerca de nuestra relación con las técnicas del transporte.

Los estudios reunidos en el presente número monográfico forman parte de este trabajo de investigación. Algunos de ellos examinan, a la luz de la historia cultural o de la semiótica cultural, redes y prácticas ejemplares del transporte en América Latina así como los discursos relativos a ellas. Al analizar la descripción física y estadística del territorio argentino que publicó a mediados del siglo XIX el viajero francés Martin de Moussy, Mario Sebastián Román destaca la importancia que este geógrafo atribuía a los medios de transporte, en particular al ferrocarril susceptible de crear «en un instante ciudades, pueblos y aldeas, es decir, población». Una exaltación semejante de los nuevos vehículos motorizados se puede desprender de las fotografías y tarjetas postales examinadas por Hinnerk Onken: numerosas imágenes de medios e infraestructuras de transporte que circularon a principios del siglo XX subrayaban la modernidad de Sudamérica, pero mostraban también, de manera más o menos indirecta, que la aceleración del tránsito se había logrado a costa de las culturas indígenas. Si bien los discursos políticos, económicos e ingenieriles tienden a exaltar el progreso de los transportes, otros documentos como la caricatura o la crónica urbana dejan vislumbrar el impacto de la modernización técnica en las prácticas cotidianas. Como muestran Guillermo Giucci y Tomás Errázuriz, en las ciudades sudamericanas de la primera mitad del siglo XX el tranvía y el autobús dieron lugar a un viaje colectivo relativamente disciplinado, pero también estorbado por retrasos angustiantes y por mirones o manoseadores impertinentes. Con respecto a los transportes actuales de Bogotá, Juan Carlos Mendoza-Collazos insiste por su parte en lo indeterminable de la interacción entre medios de locomoción y pasajeros urbanos: los torniquetes y los asideros del nuevo Transmilenio no les impiden a los usuarios de evitar el pago o de acumularse en la zona de ingreso. Tales prácticas favorecen la construcción de una particular identidad cultural latinoamericana en cuanto a los sistemas del transporte, cuyas características consisten, según Juan Manuel Montoro y Sebastián Moreno Barreneche, no solo en semejantes interacciones irregulares, sino también en la no-linealidad de los trayectos por un territorio sumamente extenso y accidentado.

Las repercusiones complejas de ciertos vehículos modernos siempre han sido un gran tema de la literatura latinoamericana. Ya ocupan un lugar muy importante en la poesía modernista, como detalla el ensayo de Kurt Hahn: igual que su contemporáneo José Martí, el gran viajero Rubén Darío celebra la velocidad de los trenes y los automóviles, pero lo hace en una forma romántica que oculta la materialidad técnica de estos medios de locomoción. Varios escritores del siglo XX, en cambio, se ponen a explorar el potencial poético de tales máquinas rodantes. Un caso ejemplar, estudiado por Alan Pérez Medrano, es el mexicano Fernando del Paso, cuya novela José Trigo, ubicada en el mundo ferrocarrilero, incluye una larga oda a los trenes y su paisaje sonoro, mientras que el Poema Sujo del brasileño Ferreira Gullar evoca la música que se puede escuchar «caminando por los 
rieles». Una visión menos eufórica del tránsito moderno se manifiesta en la narrativa del venezolano Adriano González León, presentada por Anamaría Lopez-Abadía como un crítico acerbo del discurso progresista vinculado con la motorización general: a sus personajes poco heroicos, el automóvil no les parece una extensión poderosa del propio cuerpo, sino al contrario un dispositivo deshumanizante que convierte al conductor o al pasajero en «una pieza más». Ante experiencias no menos descentrantes que hace en el Métro de París y en el Subway de New York, el poeta chileno Enrique Lihn afirma que la hipermovilidad del tránsito metropolitano obstaculiza la escritura lírica; en varios poemas, analizadas por Henriette Terpe, desmiente el entusiasmo cosmopolita de las vanguardias latinoamericanas y termina por constatar que, escribiendo sobre ciudades extranjeras, al final «nunca sal[ió] de nada». Tampoco el novelista argentino Hernán Ronsino comparte la dromolatría vanguardista cuando en su así llamada «trilogía pampeana» evoca los vehículos típicos de un pueblo de provincia. Como intenta exponer el autor de la presente introducción, esta imaginada cultura periférica abunda en medios de transporte anacrónicos que tienden a provocar violentas transgresiones.

El cine se presta aún más que la literatura a indagar las culturas de la movilidad técnica, ya que él mismo se produce con aparatos movibles y se compone de imágenes móviles. A veces, este medio aparecido casi simultáneamente con el automóvil y el avión aprovecha su gran popularidad para convertir en mitos ciertos hitos en la historia del transporte. Gonzalo Aguilar lo ejemplifica mediante Pulqui II, el primer (y último) avión a reacción de industria argentina: varias películas estrenadas a principios del siglo XXI presentan este aparato apenas empleado, desarrollado por ingenieros alemanes y provisto de motores ingleses, como emblema de la gran potencia latente del estado peronista. Una imagen mucho más matizada de los medios de transporte modernos se puede desprender del cine experimental de Fernando Birri: en su documental Tire dié, analizado por Christian Wehr, el director argentino contrasta la vista aérea de la ciudad de Santa Fe, metáfora de una mirada totalizante sobre la sociedad urbana, con la visión dinámica de niños pobres desde el tren atravesando los arrabales, más apta para despertar la indignación del público. El paralelo entre los desplazamientos de los vehículos mostrados y los movimientos de la cámara se destaca de modo especialmente sugestivo en la 〈película fluvial〉 estudiada por Christian von Tschilschke: obras tan diferentes como El abrazo de la serpiente del colombiano Ciro Guerra, donde se explora la mitología amazónica del río, o Historias extraordinarias del argentino Mariano Llinás, que evoca con sorna el proyecto fracasado del Corredor Fluvial Pampeano, coinciden en la superposición plástica de tres medios, a saber, el medio natural de la vía fluvial, la embarcación que avanza en ella y, tercero, el mismo cine, este medio de comunicación tan capaz de provocar la inmersión del espectador. Cuanto más difícil el transporte filmado, tanto más grande su potencial dramático: lo prueban numerosas películas sobre tentativas clandestinas de cruzar la frontera entre México y Estados Unidos. En su estudio del corpus respectivo, Teresa Hiergeist subraya la constante deficiencia espectacular de los vehículos y caminos empleados por los protagonistas, pero también la variedad de su puesta en escena: mientras que producciones nacionales intentan desalentar a los emigrantes ilegales, películas más independientes tienden a exaltar lo heroico o lo ingenioso de un tráfico fronterizo sumamente obstaculizado. Con igual insistencia, pero desde una perspectiva inversa, la película de carretera cubana, estudiada por Nadia Lie, asigna un papel político a los autos protagónicos. Si bien en Guantanamera, de Tomás Gutiérrez Alea, el 
taxi es presentado como un microcosmos social y un lugar de controversias en medio de un estado autoritario con fronteras cerradas, en Personal belongings, de Alejandro Brugués, solamente le sirve al protagonista solitario para distanciarse de un paisaje desolador que quiere abandonar a toda costa. Una tal función consoladora o libertadora se vincula desde siempre con la bicicleta que es, según las pesquisas de Jörg Türschmann, un vehículo muy presente en el cine latinoamericano contemporáneo: mientras que en La bicicleta de los Huanca, una ya clásica comedia boliviana, el vehículo protagónico crea un mundo al revés dónde las mujeres ejercen el mando, en la película chilena Velódromo, de Alberto Fuguet, le permite al protagonista desesperado vivir momentos de felicidad.

El horizonte de la reflexión sobre las culturas del transporte se alarga en dos estudios que cierran el presente número monográfico. En su lectura de dos relaciones del siglo XVI, relativas al descubrimiento del río Amazonas y a la búsqueda del legendario El Dorado, Hermann Doetsch destaca la importancia de las redes de transporte para la construcción del Estado moderno: como ya lo observaron los cronistas coetáneos, la expansión del imperio español en el Nuevo Mundo no hubiera sido posible sin el empleo estratégico de la navegación fluvial, pese al uso transgresivo siempre posible de esta infraestructura a la vez natural y artificial por rebeldes como Lope de Aguirre. Tales prácticas no consideradas en teorías militares, económicas o técnicas del transporte están al centro de las discusiones actuales sobre la movilidad que, conforme a Dhan Zunino Singh, sin embargo no pueden prescindir de la historia cultural, literaria y cinematográfica del transporte, dado que solamente por tales rodeos se hace patente lo multifacético de la locomoción vehicular, apenas visible en la rutina cotidiana del conductor o pasajero.

En su mayor parte, los trabajos aquí reunidos han sido presentados en el XXII Congreso de la Asociación Alemana de Hispanistas que se celebró en Berlín del 27 al 31 de marzo de 2019, en un momento todavía más propicio para los encuentros internacionales. Por lo tanto, quisiera agradecer, también en el nombre de los otros coordinadores, a la Asociación Alemana de Hispanistas cuyo apoyo generoso facilitó la conversación transatlántica presencial. Además, quedamos agradecidos a las universidades de Colonia, de Viena y de Wurzburgo por sus subsidios para la publicación. En fin, reconocemos la contribución de Ceylan Küfner y de Henriette Terpe, que se encargaron de la redacción de los textos.

\section{REFERENCIAS BIBLIOGRÁFICAS}

BARTHES, R. ([1963] 1993) «Mythologie de l'automobile». En CEuvres complètes, ed. Éric Marty, Paris: Seuil 1993, t. 1, p. 1136-1142.

CRESSWELL, T. (2006) On the move. Mobility in the modern Western world. New York: Routledge. DIVALL, C./REVILL, G. (2005) «Cultures of transport: representations, practice and technology», Journal of transport history 26, p. 99-117.

GIUCCI, G (2007) La vida cultural del automóvil. Rutas de la modernidad cinética. Buenos Aires: Prometeo.

GIUCCI, G./ERRÁZURIZ, T. (2018) El viaje colectivo. La cultura del tranvía y del ómnibus en América del Sur. 1900-1950. Talca/Santiago de Chile: Bifurcaciones/Campus creativo.

INNIS, H. A. ([1952] 1991) The bias of communication. Toronto: University of Toronto Press. 
LAFITTE, J. ([1932] 1972) Réflexions sur la science des machines. Guillerme, J. (ed.) París: Vrin.

LATOUR, B. (1999) «A collective of humans and nonhumans. Following Daedalus's labyrinth». En: Pandora's hope. Essays on the reality of science studies. Cambridge (Mass.): Harvard University Press, p. 174-215.

NITSCH, W. (2011) «Un imperio de comunicaciones. La técnica precolombina en los Comentarios reales». En: José Morales Saravia/Gerhard Penzkofer (eds.): El Inca Garcilaso de la Vega: entre varios mundos. Lima: Universidad Nacional Mayor de San Marcos, p. 265-281.

ORTIZ CASSIANI, J. (2018) Un diablo al que le llaman tren. El ferrocarril Cartagena-Calamar, Bogotá: Fondo de Cultura Económica.

PAYRÓ, J. ([1933] 2005) «Vlaminck, el pintor ciclista» (1933). En Contra. La revista de los francotiradores, ed. Sylvia Saítta, Buenos Aires: Universidad Nacional de Quilmes, pp. 49-52.

PIGLIA, M (2014) Autos, rutas y turismo. El Automóvil Club Argentino y el estado. Buenos Aires: Siglo XXI.

ZUNINO SINGH, D./GIUCCI, G./JIRÓN, P. (2017) Términos clave para los estudios de movilidad en América Latina- Buenos Aires: Biblos. 